\title{
O presente e o futuro dos marcadores circulantes de câncer
}

\author{
Gilda Alves, ${ }^{1 *}$ Lucas Delmonico ${ }^{1}$
}

\section{Resumo}

Para alguns tipos de câncer, existem marcadores circulantes em uso que não apresentam especificidade e sensibilidade suficientes. Por isso, novas tecnologias e novos conhecimentos estão emergindo com o objetivo de encontrar os marcadores circulantes ideais para cada subtipo de câncer. Recentemente importantes avanços na pesquisa clínica permitiram a identificação de DNA, RNA, proteínas livres no plasma, na saliva, em descarga mamilar e na urina como potenciais e promissores marcadores para o câncer. Outra possível fonte de marcadores circulantes são as vesículas extracelulares, que têm um papel importante na comunicação celular. Em vista das novas descobertas, algumas das quais reunidas nesta revisão de literatura, os conceitos tradicionais de metástase e de micrometástase merecem ser revistos.

Descritores: Metástase neoplásica; Diagnóstico; Plasma; Mama; Saliva; Urina.

\section{Abstract \\ The present and the future of circulating cancer markers}

For some types of cancer, there are circulating markers in use that don't have sufficient specificity and sensitivity. New technologies and new knowledge are thus emerging in order to find the ideal circulating markers for each cancer subtype. Important recent advances in clinical research have allowed for the identification of free circulating DNA, RNA, and proteins from plasma, saliva, nipple aspirate fluid, and urine as potential and promising circulating markers of cancer. Another possible source of circulating markers are the extracellular vesicles, which play an important role in cell communication. Considering new discoveries, some of which are presented in this review, the traditional models of metastasis and micrometastasis deserve to be reviewed.

Keywords: Neoplasm metastasis; Diagnosis; Plasma; Saliva; Breast; Urine.

1. Laboratório de Marcadores Circulantes. Departamento de
Patologia Geral e Laboratórios. Faculdade de Ciências Médicas.
Universidade do Estado do Rio de Janeiro. Rio de Janeiro, RJ, Brasil.

*Endereço para correspondência:

Laboratório de Marcadores Circulantes,

Departamento de Patologia Geral e Laboratórios, FCM, UERJ

Boulevard 28 de Setembro, 77, 40 andar

Rio de Janeiro, RJ, Brasil. CEP: 20550-170.

E-mail: fgalvesbrown@gmail.com

Revista HUPE, Rio de Janeiro, 2015;14(Supl. 1):66-72

doi: 10.12957/rhupe.2015.17929

Recebido em 28/07/2015. Aprovado em 01/10/2015.

\section{Resumen}

\section{El presente y el futuro de los marcadores circulan-} tes de cáncer

Para algunos tipos de cáncer, hay marcadores circulantes en uso que tienen especificidad y sensibilidad insuficiente. Por lo tanto, las nuevas tecnologías y los nuevos conocimientos surgen con el fin de encontrar los marcadores circulantes ideales para cada subtipo de cáncer. Recientemente, los avances significativos en la investigación clínica llevaron a la identificatión de DNA, RNA y proteínas libres circulantes en plasma, saliva, secreción del pezón, y orina como posibles y prometedores marcadores de cáncer. Otra posible fuente de marcadores circulantes son las vesículas extracelulares, que desempeñan un papel importante en la comunicación celular. Teniendo en cuenta los nuevos descubrimientos, algunos de los que se ajuntan a esta revisión de la literatura; los modelos tradicionales de metástasis y micrometástasis merecen ser revisados.

Palabras clave: Metástasis de la neoplasia; Diagnóstico; Plasma; Saliva; Mama; Orina. 


\section{A antiga e a nova geração de marcadores circulantes para o câncer}

Atualmente existe um pequeno grupo de biomarcadores que é utilizado no rastreamento e no acompanhamento de alguns tipos tumorais - embora, em uso, eles sejam vistos como os biomarcadores circulantes da antiga geração, por constituírem proteínas que podem ser medidas no plasma ou no soro (Tabela 1). Todas essas proteínas são encontradas no soro de indivíduos sem câncer em baixa concentração. Contudo, esses marcadores nem sempre são encontrados em concentração aumentada em pacientes com câncer. Por exemplo, a sensibilidade do cancer antigen (CA) 15.3 como marcador de metástase de câncer de mama é de apenas 60\% a $70 \%{ }^{1}$

Cada vez mais se nota que os tumores malignos não somente alteram o microambiente ao seu redor, a fim de favorecer o seu crescimento, mas também são capazes de causar alterações sistêmicas, muitas das quais detectadas nos fluidos biológicos a partir de uma variedade de métodos. A nova geração de biomarcadores está chegando, através de um número enorme de pesquisas com o propósito da descoberta de novos biomarcadores circulantes que sejam mais sensíveis e subtipoespecíficos. A realização de testes de pesquisa de biomarcadores circulantes do câncer é chamada de biópsia líquida.

A pesquisa da nova geração de biomarcadores circulantes lança mão das ferramentas de grande porte (para grandes quantidades), que incluem a genômica (pesquisa de genes), a transcriptômica (pesquisa de $\mathrm{RNA}_{\mathrm{m}}$ ) e proteômica (pesquisa de proteínas). Porém, em alguns casos, um pequeno grupo de moléculas pode ser estudado, com ferramentas mais simples, e ser capaz de resolver a questão. Instabilidades cromossômicas, reativação da telomerase e alterações epigenéticas, como a metilação no DNA, estão entre os alvos de pesquisa.

\section{As várias formas de biópsia líquida}

A importância da falha do mecanismo normal da apoptose nas células tumorais levou algumas décadas para ser reconhecida. Da mesma forma, as vesículas extracelulares (EV) - do inglês, extracelular vesicles ficaram no fundo do armário da ciência por muitos anos. Por muito tempo, as EV foram tratadas como irrelevantes e tinham um certo significado de lixo. Entretanto, detetives que se prezam devem por vezes buscar suas evidências no lixo e não raro encontram alguma pista. Estudos recentes revelaram que as EV constituem-se numa forma normal de comunicação intercelular, inclusive a distância, desempenhando um papel importante.,9

A carga das EV é variável, podendo conter pedaços de DNA genômico, micro-RNA, RNA não codificante (ncRNA, non-coding), e mais raramente $\mathrm{RNA}_{\mathrm{m}}$ íntegro, RNAs do sistema de tradução (transportador e ribossomais), DNA mitocondrial, lipídeos etc.,9,10,11 A nomenclatura das EV também pode apresentar variações, sobretudo em trabalhos mais antigos. ${ }^{10} \mathrm{EV}$ podem, inclusive, carregar moléculas que promovem a invasividade tumoral. ${ }^{12}$

Chama a atenção que elementos de transposição tenham sido encontrados em EV. ${ }^{13}$ Elementos de transposição do tipo retroelementos (semelhantes aos retrovírus) fazem parte do genoma de todas as espécies, no qual, normalmente, ficam silenciados. Porém, algumas vezes, esses retroelementos "pulam" de lugar, ou seja, movem-se. O local de inserção não se sabe ao certo e, por isso, eles podem causar mutação ou rearranjos cromossômicos. ${ }^{14,15}$ Apesar de parecerem ser "do mal", imagina-se que os retroelementos sejam parcialmente responsáveis pela evolução das espécies. Não sabemos

Tabela 1. Marcadores circulantes de câncer em uso atualmente (2015).

\begin{tabular}{|c|c|c|c|}
\hline $\begin{array}{c}\text { Marcador } \\
\text { (sigla) }\end{array}$ & $\begin{array}{l}\text { Marcador } \\
\text { (nome) }\end{array}$ & Tumor & Ref. \\
\hline 15.3 & cancer antigen 15.3 & câncer de mama & [2] \\
\hline CA125 & carcinoma antigen 125 & câncer de ovário & [3] \\
\hline CEA & carcinoembryonic antigen & câncer colorretal & [4] \\
\hline AFP & alpha-fetoprotein & hepatocarcinoma & [5] \\
\hline CA19-9 & carbohydrate antigen 19-9 & hepatocarcinoma & [5] \\
\hline PSA & prostate specific antigen & câncer de próstata & {$[6]$} \\
\hline
\end{tabular}




\section{Artigo de revisão}

qual seria o papel dos retroelementos enviados pelos $\mathrm{EV}$, mas pode ser um elemento causador de mutação ou carregar consigo uma mensagem (um pedação de DNA) da célula doadora. ${ }^{11}$ Essa hipótese já havia sido aventurada anteriormente. ${ }^{16}$

As células-alvo podem ser de vários tipos histológicos, o que demonstra claramente o caráter sistêmico do câncer. Foi demonstrado, por exemplo, que células tumorais são capazes de transferir RNA mutante para as plaquetas in vitro e in vivo através das EV. ${ }^{17}$ Assim, todo o conceito de tumor localizado ou de localmente avançado deve ser questionado diante desse fato. Isto poderia explicar, pelo menos em parte, o fracasso no tratamento dos tumores malignos ditos pequenos e localizados.

As EV puderam ser subclassificadas de acordo com o seu tamanho e função. O tamanho das EV determina o método de isolamento. As menores EV conhecidas são os exossomos, que medem de 40-100 nm de diâmetro. Estes são formados no compartimento endossomal e são secretadas quando o corpúsculo alcança a membrana plasmática. Essas EV são secretadas por praticamente todas as células e são consideradas como mensageiros intercelulares. ${ }^{7,9} \mathrm{O}$ protocolo mais comum de isolamento dos exossomos envolve centrifugações sequenciais que começam com a velocidade de $300 \mathrm{xg}$, passando por $10.000 \mathrm{xg}, 16.000 \mathrm{xg}$ até chegar em $100.000 \mathrm{xg}$. Ou seja, velocidades muito altas somente alcançadas por ultracentrífugas. Alguns protocolos ainda utilizam um gradiente de sacarose para aumentar o grau de purificação. Portanto, por enquanto, a preparação dos exossomos é laboriosa. Para saber mais sobre os exossomos recomenda-se consultar as páginas www.exosomeseminars.com e www.exocarta.org.

Os oncossomos foram definidos como microvesículas que promovem a transferência de DNA transformante entre as células. Os oncossomos são maiores que os exossomos. Foram descobertos em gliomas que expressam a forma truncada e oncogênia do receptor de fator de crescimento epidermal (EGFRvIII), que é transferido para normais da glia, induzindo a transformação morfológica. Portanto, os oncossomos podem contribuir para a propagação vertical de oncogenes, assim como a alteração do microambiente. . $18,19^{2}$

Outra fonte de biomarcadores de câncer que está sendo explorada é constituída das células tumorais circulantes (CTC) - do inglês, circulating tumor cells. As CTC são células intactas que podem ser purificadas do sangue em função das características fisioquímicas da sua membrana que as distinguem das células normais.
A identificação das CTC não deixa dúvidas de que metástases, às vezes micrometástases, estão circulando no sangue periférico. Logo, a caracterização molecular das CTC pode demonstrar a existência de subpopulações ou subclones. ${ }^{20}$

O DNA tumoral circulante (ctDNA) - do inglês circulating tumor DNA - pode ser encontrado circulando livremente, tal como as proteínas. ${ }^{7}$ Usando PCR digital, ctDNA de origem tumoral foi detectado em mais de 75\% dos pacientes com câncer avançado de pâncreas, ovários, colorretal, bexiga, gastroesofaríngeo, mama, melanoma, hepatocelular e de cabeça e pescoço. ${ }^{1} \mathrm{Em}$ pacientes com tumores localizados, ctDNA foi detectado em 73\%, 57\%, 48\% e 50\%, dos pacientes com câncer colorretal, gastroesofaríngeo, pancreático e de mama, respectivamente. ${ }^{1}$ Normalmente os ctDNAs são compostos de pequenos fragmentos, mas mostram-se clinicamente importantes por determinarem o tratamento ou estarem associados à resistência ao mesmo. ${ }^{21,22}$ RNAs circulantes (exRNA) - do inglês, external RNA - também foram relatadas. Mais informações sobre a função dos exRNAs podem ser acessadas pela página exrna.org.

O mecanismo que governa a produção dos ctDNAs, assim como os exRNAs, não é bem compreendido. É provável que esses ácidos nucleicos circulantes tenham mais de uma origem, inclusive a partir das CTC.

Entre as ferramentas de pesquisa mais modernas, a proteômica tem merecido certo destaque na procura de biomarcadores circulantes de câncer de nova geração. O termo 'proteômica' é utilizado para descrever a análise sistemática de proteínas e suas características, quantidades e funções; por sua vez, o termo 'proteoma' foi definido pela primeira vez como o "conjunto de proteínas expressas por um genoma, uma célula ou um tecido". ${ }^{23,24}$

A aplicação moderna da espectrometria de massas (MS) para identificação de sequências peptídicas tornou-se a melhor maneira de análise do perfil proteico. As proteínas são partículas carregadas que quando submetidas a um campo magnético ou no vácuo possuem uma dinâmica muito precisa. Dessa forma, a MS baseia-se comumente na fragmentação das proteínas em peptídeos curtos, que posteriormente são ionizados seguindo diferentes tecnologias (gás inerte em spray ou laser) e acelerados em um campo elétrico para possível detecção. Frequentemente, estes espectrômetros formam conjuntos sequenciais (MS/MS), permitindo que o primeiro faça a clivagem preferencialmente nas ligações peptídicas gerando uma escala de fragmentos, cada um diferenciando-se 
por apenas um único aminoácido. O segundo separa os fragmentos e os apresenta com suas massas, sendo que a sequência de aminoácidos de um peptídeo pode ser deduzida a partir das massas reveladas. A informação obtida é confrontada a um banco de dados de sequências já conhecidas e feita uma combinação de maior veracidade e cobertura de leitura proteica.

São várias as opções de origem e composição dos marcadores circulantes. Além disso, ainda temos variações tecnológicas e uma diversidade de fluidos. No momento, há certa disputa entre plasma ou soro e saliva, sobre qual destes seria o melhor fluido com o propósito de detecção dos biomarcadores circulantes de câncer. Com respeito especificamente ao câncer de mama, o nipple aspirate fluid (NAF, ou líquido aspirado do mamilo em tradução livre) tem sido apontado como uma alternativa viável. A urina, sobretudo quanto aos tumores urológicos, aparece entre algumas preferências. Evidentemente, cada um desses fluidos oferece vantagens e desvantagens no atual cenário.

\section{Plasma}

O plasma é abundante em proteínas, muitas delas bem caracterizadas e que atuam em diversas condições fisiológicas; como exemplo, a ferritina, transferrina, creatina, entre outras. Outro grupo de proteínas foi caracterizado como marcadoras de inflamação, abrangendo proteínas de funcionalidades diversas. A albumina é considerada a de maior expressão quantitativa e junto a ela imunoglobulinas, hormônios, lipoproteínas e outros compostos podem ser igualmente identificados. Em resposta às diversas situações patológicas, como infecções e neoplasias, a composição do plasma, assim como a concentração das proteínas, pode(m) ser alterada(s), tornando o plasma ou o soro um fluido-alvo de muitas pesquisas. Servindo a esse propósito, foi criado o banco de dados de proteoma de plasma (PPD - do inglês, plasma proteome database): www.plasmaproteomedatabase.org, como parte do Human Proteome Organization (HUPO). O PPD contém dados qualitativos e quantitativos sobre as proteínas do plasma e do soro e, portanto, serve como uma plataforma de referência para a descoberta de novos biomarcadores. Além disso, as proteínas que foram encontradas em EV isoladas de plasma estão também disponíveis. A consulta ao banco de dados PPD foi projetada para ser feita de forma individual ou em grupo, a partir de genes, do PubMed, acessos do RefSeq, identificações do UniProt ou de sequências peptídicas.
Cada uma das proteínas está ligada a bancos externos de busca, tais como Entrez Gene, Human Protein Reference Database (HPRD) - ou Banco de dados de referência de Proteína Humana -, UniProt e NetPath.

A plataforma proteômica Matrix-assisted laser desorption/ionization time of flight(ClinProt/MALDI-TOF) é capaz de detectar peptídeos diferencialmente expressos a partir de uma seleção feita por contas magnéticas. Em colaboração com pesquisadores italianos e utilizando a plataforma ClinProt/MALDI, o nosso grupo encontrou dois peptídeos que estavam subexpressos em plasma de pacientes com carcinoma epidermoide de pênis. Esses peptídeos foram identificados como sendo fragmentos das proteínas do sistema de complemento $\mathrm{C} 3$ e C4a/b. ${ }^{25}$ Novos experimentos serão realizados para validar as proteínas C3 e C4a/b como biomarcadores do carcinoma epidermoide de pênis, utilizando amostras de plasma.

\section{Saliva}

A saliva é um fluido funcional de proteção da mucosa oral e de iniciação do processo da digestão, que é produzida por três glândulas secretoras (parótida, submandibular e sublingual). Entre os componentes funcionais, encontram-se o bicarbonato, que acidifica a cavidade oral contra os patógenos causadores das cáries dentárias, e as glicoproteínas, que também promovem um ambiente hostil aos agentes nocivos. Além destes, as amilases presentes são essenciais para a quebra inicial da cadeia dos amidos. ${ }^{26}$

Até alguns anos atrás a saliva era considerada apenas como um fluido coadjuvante ao sistema digestório. No entanto, a saliva tem se tornado uma nova alternativa de busca por biomarcadores que possam revelar doenças locais e sistêmicas. Os vasos sanguíneos que infiltram as glândulas salivares seriam responsáveis pelo transporte de biomoléculas contidas no sangue periférico, levando assim a constituir parte do fluido. Nesse sentido, testes laboratoriais foram desenvolvidos utilizando saliva para quantificar proteínas e hormônios (cortisol, deidroepiandrosterona, progesterona, testosterona, estradiol e estriol), assim como para a detecção de anticorpos do vírus de imunodeficiência humano 1 e 2 (HIV-1 e HIV-2). Nesses casos, a coleta de saliva como fluido para o diagnóstico provou ser simples e adequada, com alta sensibilidade e especificidade.

As vantagens do uso da saliva como ferramenta diagnóstica englobam uma série de fatores: a coleta é segura, ausente de punções e aspirações por agulha fina; 


\section{Artigo de revisão}

não invasiva e podendo ser coletada repetidas vezes sem desconforto do paciente. Além do mais, é um líquido com menor complexidade quando comparado ao sangue periférico, capaz de conter as mesmas proteínas, e representar fielmente o estado patológico do indivíduo. Em resumo, a fisiologia da cavidade oral permite que o fluxo salivar seja contínuo e esteja de acordo com o estado metabólico do indivíduo, podendo apresentar biomarcadores constantemente em condições igualitárias em relação aos demais fluidos. ${ }^{27}$

Um catálogo completo das proteínas da saliva está disponível e pode ser encontrado na página www.hspp.ucla.edu/spkbintro.html. A análise sistemática dos componentes da saliva revelou a estrutura, a função e as modificações pós-tradicionais de cada uma.

Apesar das melhorias advindas do uso da mamografia para o rastreamento do câncer de mama no Brasil, as limitações para o diagnóstico precoce ainda são diversas, contribuindo para elevadas taxas de mortalidade. ${ }^{28}$ No intuito de melhorar esse quadro, pesquisas recentes destacaram a presença de proteínas e $\mathrm{RNA}_{\mathrm{m}}$ diferencialmente expressos nos casos de carcinomas mamários quando comparados aos grupos-controles, porém enfatizam a necessidade de aperfeiçoamento e validação dos biomarcadores encontrados..29,30,31 Já foi possível detectar o marcador human epidermal growth factor receptor 2 (HER2) solúvel em saliva de pacientes de subgrupo de pacientes de câncer de mama. ${ }^{32,33}$ Contudo, a aplicação da detecção do HER2 em saliva apresentou uma série de contrapontos e precisa ser mais pesquisada. ${ }^{34}$

\section{Fluido aspirado da mama - NAF}

O epitélio mamário é formado pelas células dos ductos e lóbulos que estão constantemente secretando e absorvendo o NAF. ${ }^{35} \mathrm{O}$ crescimento excessivo e a esfoliação do epitélio mamário resultam de uma gama de fatores, em especial da exposição aumentada de hormônios. Dessa forma é esperado que neste fluido sejam encontradas células de descamação e que estas tragam respostas sobre a fisiopatologia da mama. Além disso, o NAF é composto de uma série de proteínas que incluem lactoalbuminas, fatores de crescimento, carboidratos, tais como lactose, lipídios, colesterol, hormônios como estrógenos, andrógenos, progesterona e prolactinas, os quais enriquecem o fluido e o tornam um forte promissor para pesquisa de novos biomarcadores. ${ }^{36}$

Os primeiros estudos com NAF que descrevem as características citopatológicas e a sua utilização na clínica datam de 1958. Desde então, outros trabalhos foram surgindo com a evolução das técnicas moleculares e diversas proteínas foram sendo apontadas ao longo dos anos como sugestivas de biomarcadores para o câncer de mama, como exemplo, a prolactin inducible protein e a gross cystic disease fluid protein. ${ }^{37}$

Nos últimos anos o NAF tem ganhado destaque novamente pela introdução da biópsia líquida e o avanço das tecnologias aplicadas à proteômica. A coleta do fluido, justamente por ser de baixo custo, tem despertado o interesse na clínica para investigação; porém, a coleta ainda é dolorosa e feita por meio de bombas a vácuo, que geram quantidades mínimas do fluido para pesquisa laboratorial. Neste ano, nosso grupo publicou um artigo descrevendo uma nova alternativa de coleta, de forma simples e não dolorosa, que revelou proteínas em comum ao método tradicional de coleta. ${ }^{38}$ Essa alternativa envolve a absorção do NAF pelo cartão Guthrie (o mesmo usado no teste do pezinho). A confirmação foi feita por proteômica usando um quadrople time of fligth (Q-TOF).

Até o momento não existem trabalhos que descrevam com segurança as taxas de sensibilidade e especificidade para as proteínas reveladas no NAF. O que tem-se observado é um desmembramento das proteínas em classes e suas caracterizações de predominância no fluido. É esperado que nos próximos anos diversas dessas proteínas descritas, assim como outras que vierem a ser reveladas, atuem como biomarcadoras para os subtipos moleculares dos tumores mamários.

\section{Urina}

A análise de urina constitui-se num método não invasivo de análise clínica e tem sido utilizado principalmente para controlar doenças do trato urogenital. Em um período de 24 horas, a urina normal produz cerca de 150 mg de proteínas e peptídeos (peso < 10 kDa), que são derivados de uma variedade de fontes. A maioria das proteínas/peptídeos advêm do filtrado glomerular do plasma, enquanto uma parte é oriunda do processo de apoptose e da clivagem de proteínas de membrana que são secretadas. Peptídeos e, mesmo, proteínas de elevado peso molecular (albumina, por exemplo) são capazes de passar através do glomérulo e constituir uma fonte importante de informação sobre a saúde. Normalmente, os peptídeos resultam da proteólise de proteínas maiores que circulam no plasma. Assim, a urina é especialmente atrativa para a descoberta de 
biomarcadores em doenças urológicas. ${ }^{39}$

Surface Enhanced Laser Desorption Ionization Time of Flight (SELDI-TOF) é outro tipo de plataforma proteômica, capaz de selecionar proteínas ou peptídeos a partir das propriedades de ligação. Trata-se de um método de separação de proteínas por afinidade de acordo com suas propriedades físicas (hidrofóbicas, hidrofílicas, ácidas, básicas, com afinidade por metal etc.), que podem ser ligadas seletivamente a uma superfície sólida de metal (chip de proteína). O SELDI tem como vantagem a capacidade de detectar proteínas de fluidos, como a urina, sem tratamento prévio. Nosso grupo, em colaboração com um grupo alemão, e usando a plataforma SELDI-TOF, relatou a subexpressão das proteínas K-12 e MASP-2 em urina de pacientes de carcinoma renal (RCC - do inglês, renal cell carcinoma) de células claras. ${ }^{40}$ Esses resultados, embora promissores, precisam ainda ser validados numa coorte maior de pacientes de RCC e células claras (principal tipo histológico), e em outros subtipos de RCC.

\section{Considerações finais}

Considerando que a troca de material genético ocorre a distância e entre células que não são do mesmo tecido, o conceito tradicional de metástase (via célula) e das vias de metástase deveria ser revisto. Será que a metástase pode se dar por via de moléculas ou de pequenas vesículas ao invés de células tumorais? Atualmente não sabemos ao certo.

Seria muito interessante fazermos uma revisão desse artigo daqui a dez anos. Com certeza, muitas descobertas de novos biomarcadores circulantes já terão sido feitas e algumas delas já terão sido validadas para uso clínico. Qual fluido será o melhor? Qual tipo de molécula ou de método será o melhor? Como o câncer é uma doença altamente complexa, acreditamos que as respostas a essas perguntas deverão ser tumorespecíficas.

A tendência atual é chegarmos à medicina personalizada para o tratamento da doença. Até lá, potenciais biomarcadores precisam ser testados, considerando a validação clínica. Vamos aguardar.Sem dúvidas, em dez anos estaremos diante de outra realidade no combate ao câncer.

\section{Referências}

1. Bettegowda C, Sausen M, Leary RJ, et al. Detection of circulating tumor DNA in early- and late-stage human malignancies. Sci Transl Med. 2014;19;6(224):224ra24.
2. Misek DE, Kim EH. Protein biomarkers for the early detection of breast cancer. Int J Proteomics. 2011;343582.

3. Bast RC Jr, Klug TL, St John E, et al. A radioimmunoassay using a monoclonal antibody to monitor the course of epithelial ovarian cancer. N Engl J Med. 1983;13;309(15):883-7.

4. Yan L, Xie F, Yang C, et al. The comparison of surgical patients with primary hepatic squamous cell carcinoma or adenosquamous carcinoma and surgical patients with hepatocellular carcinoma. World J Surg Oncol. 2015;28;13(1):90.

5. Desch CE, Benson AB 3rd, Somerfield MR, et al. American Society of Clinical Oncology. Colorectal cancer surveillance: 2005 update of in American Society of Clinical Oncology practice guideline. J Clin Oncol. 2005; 20;23(33):8512-9.

6. Esfahani M, Ataei N, Panjehpour M. Biomarkers for evaluation of prostate cancer prognosis. Asian Pac J Cancer Prev. 2015;16(7):2601-2611.

7. Kinet V, Halkein J, Dirkx E, et al. Cardiovascular extracellular microRNAs: emerging diagnostic markers and mechanisms of cell-to-cell RNA communication. Front Genet. 2013;12(4):214.

8. Peinado H, Alečković M, Lavotshkin S, et al. Melanoma exosomes educate bone marrow progenitor cells toward a pro-metastatic phenotype through MET. Nat Med. 2012;18(6):883-91.

9. Van der Vos KE, Balaj L, Skog J, et al. Brain tumor microvesicles: insights into intercellular communication in the nervous system. Cell Mol Neurobiol. 2011;31(6):949-59.

10. Kim DK, Lee J, Kim SR, et al. EVpedia: a community web portal for extracellular vesicles research. Bioinformatics. 2015;15;31(6):933-9.

11. Redzic JS, Balaj L, van der Vos KE, et al. Extracellular RNA mediates and marks cancer progression. Semin Cancer Biol. 2014;28:14-23.

12. McCready J, Sims JD, Chan D, et al. Secretion of extracellular hsp90alpha via exosomes increases cancer cell motility: a role for plasminogen activation. BMC Cancer. 2010;16;10:294.

13. Balaj L1, Lessard R, Dai L, et al. Tumour microvesicles contain retrotransposon elements and amplified oncogene sequences. Nat Commun. 2011;1(2):180.

14. Kazazian $\mathrm{H}$, Wong $\mathrm{C}$, Youssoufran $\mathrm{H}$, et al. Heamophilia $\mathrm{A}$ resulting from de novo insertion of $L 1$ sequences represents a novel mechanism of mutation in man. Nature. 1988;332:164-6.

15. Hermetz KE, Surti U, Cody JD, et al. A recurrent translocation is mediated by homologous recombination between HERV-H elements. Mol Cytogenet. 2012;5(1):6.

16. Alves G, Kawamura MT, Nascimento P, et al. DNA release by line-1 (L1) retrotransposon. Could it be possible? Ann N Y Acad Sci. 2000;906:129-33.

17. Nilsson RJ, Balaj L, Hulleman E, et al. Blood platelets contain tumor-derived RNA biomarkers. Blood. 2011;29;118(13):36803.

18. Al-Nedawi K, Meehan B, Micallef J, et al. Intercellular transfer of the oncogenic receptor EGFRvIll by microvesicles derived from tumour cells. Nat Cell Biol. 2008;10(5):619-24.

19. Di Vizio D, Kim J, Hager MH, et al. Oncosome formation in prostate cancer: association with a region of frequent chromosomal deletion in metastatic disease. Cancer Res. 2009;1;69(13):5601-9. 


\section{Artigo de revisão}

20. Fernandez SV, Bingham C, Fittipaldi P, et al. TP53 mutations detected in circulating tumor cells present in the blood of metastatic triple negative breast cancer patients. Breast Cancer Res. 2014;9;16(5):445.

21. Murtaza M, Dawson SJ, Tsui DW, et al. Non-invasive analysis of acquired resistance to cancer therapy by sequencing of plasma DNA. Nature. 2013;2;497(7447):108-12.

22. Diaz LA Jr, Williams RT, Wu J, et al. The molecular evolution of acquired resistance to targeted EGFR blockade in colorectal cancers. Nature. 2012;28;486(7404):537-40.

23. Wasinger VC, Cordwell SJ, Cerpa-Poljak A, et al. Progress with gene-product mapping of the Mollicutes: Mycoplasma genitalium. Electrophoresis. 1995;16:1090-1094.

24. Alberts B, Johnson A, Lewis J, et al. Proteínas. Biologia molecular da célula. $5^{\circ}$ edição. Porto Alegre: Artmed; 2010. 125-193.

25. Ornellas $P$, Ornellas AA, Chinello $C$, et al. Downregulation of C3 and C4A/B complement factor fragments in plasma from patients with squamous cell carcinoma of the penis. Int Braz J Urol. 2012;38(6):739-49.

26. Amerongen AV, Veerman EC. Saliva the defender of the oral cavity. Oral Dis. 2002;8:12-22.

27. Streckfus CF, Dubinsky WP. Proteomic analysis of saliva for cancer diagnosis. Expert Rev Proteomics. 2007;4:329-332.

28. Balabram D, Turra CM, Gobbi H. Survival of patients with operable breast cancer (Stages I-III) at a Brazilian public hospital - a closer look into cause-specific mortality. BMC Cancer. 2013;24(13):34.

29. Streckfus CF, Storthz KA, Bigler L, et al. A comparison of the proteomic expression in pooled saliva specimens from individuals diagnosed with ductal carcinoma of the breast with and without lymph node involvement. J Oncol. 2009;737619.

30. Zhang L, Xiao H, Karlan S, et al. Discovery and preclinical validation of salivary transcriptomic and proteomic biomarkers for the non-invasive detection of breast cancer. PLoS One. 2010; 31:5:e15573

31. Abraham JE, Maranian MJ, Spiteri I, et al. Saliva samples are viable alternative to blood samples as source of DNA for high throughput genotyping. BMC Med Genomics. 2012;5:19.

32. Streckfus CF, Mayorga-Wark O, Arreola D, et al. Breast cancer related proteins are present in saliva and are modulated secondary to ductal carcinoma in situ of the breast. Cancer Invest. 2008;26:159-67

33. Streckfus CF, Arreola D, Edwards C, et al. Salivary protein profiles among HER2/neu-receptor-positive and -negative breast cancer patients: Support for using salivary protein profiles for modeling breast cancer progression. J Oncol. 2012;413256.

34. de Abreu Pereira D, Areias VR, Franco MF, et al. Measurement of HER2 in saliva of women in risk of breast cancer. Pathol Oncol Res. 2013;19:509-13

35. Lang JE, Kuerer HM. Breast ductal secretions: clinical features, potential uses, and possible applications. Cancer Control. 2007;14:350 359.

36. Brunoro GV, Ferreira AT, Trugilho MR, et al. Potential correlation between tumor aggressiveness and protein expression patterns of nipple aspirate fluid (NAF) revealed by gel-based proteomic analysis. Curr Top Med Chem. 2014;14(3):359-68.

37. Manello F, Tonti GA, Papa S. Human gross cyst breast disease and cystic fluid: bio-molecular, morphological, and clinical studies. Breast Cancer Res Treat. 2006;97:115-129.

38. Delmonico L, Areias VR, Pinto RC, et al. Protein identification from dried nipple aspirate fluid on Guthrie cards using mass spectrometry. Mol Med Rep. 2015;12(1):159-64.

39. Pisitkun T, Johnstone R, Knepper MA. Discovery of urinary biomarkers. Mol Cell Proteomics. 2006;5:1760-71.

40. Alves G, Pereira DA, Sandim V, et al. Urine screening by Seldi-Tof, followed by biomarker identification, in a Brazilian cohort of patients with renal cell carcinoma (RCC). Int Braz J Urol. 2013;39(2):228-39. 